\title{
Approaches of Wear Resistance Improvement of Ti-6Al-4V by Surface Modification
}

\author{
Rui-Hua $\mathrm{Hu}$ \\ Zhengzhou University of Industrial Technology, \\ Zhengzhou, China \\ e-mail:ruihuahu926@hotmail.com
}

\author{
Kui-Hua $\mathrm{Hu}$ \\ CAMA(Luoyang) Electronics Co., Ltd., \\ Luoyang, China \\ e-mail: hukh@cama-e.com
}

\begin{abstract}
To overcome the the drawbacks of poor wear resisitance of titanium and its alloys, so far many efforts have been made to improve wear resistance and some techniques have been developed. Theses techniques can be classified into two categories: surface coating and surface cladding. Surface coatings generally include BN film, diamond-like carbon films and TiN films. These surface thin layers very significantly enhance the tribological properties although the some disadvantages still exist such as the small thickness, unstable composition, and poor adherence to substrate. The most applicable achievement is surface cladding. Surface cladding overcomes the drawbacks of surface coating. Not only the thickness of the surface composite layers can be controlled but the composition of the layer can be flexiblely choiced as well. Compositions of clad layer are diversified. The bonding strength between the surface clad layer and the substrate is very high. Among those, the laser beam cladding is a cutting edge and a promising method.
\end{abstract}

Keywords-titanium; tribological property; wear resistance; surface modification; laser cladding

\section{INTRODUCTION}

Titanium and its alloys, due to their excellent properties such as high strength-to-weight ratio, good mechanical properties at elevated temperatures, corrosion resistance and biocompatibility, have been used for chemical, electric power, aerospace, automobile and medical applications. However, the main drawbacks of titanium and its alloys are their low hardness and poor resistance to sliding wear. These properties restrict their further applications. Many efforts have been made to improve the wear resistance. Surface modification is one of those methods to enhance tribological properties.

Many methods such as surface coating, surface nitriding, and surface cladding have been developed in order to improve the tribological property of titanium and its alloys. Although surface coating and surface nitriding layer are very thin films with thickness from several micrometers to hundreds micrometers, the coated samples show much improvement of wear resistance. Likewise, surface cladding shows better wear durability in circumstances of friction under high contact stress on soft substrate like $\mathrm{Ti}$ and its alloys. Surface modification methods show very effective and promising applications in engineering.

In this paper, an overview is taken to summarize these developments in recent decades in improving wear resistance by surface modification.

\section{SURFACE COATING}

\section{A. BN films on Ti-6Al-4V substrat}

As early as in 1995, Tandjaoui Baazi [1] investigated BN coating onto Ti-6Al-4V substrate synthesized by ion-implantation method and its tribo-mechanical properties. B film with thickness of $1000 \mathrm{~A}^{\circ}$ was firstly deposited on polished Ti-6Al-4V substrate by evaporating $\mathrm{B}$ using electron heating. Then the film was bombarded by $\mathrm{N} 2+$ with $50 \mathrm{keV}$ and dose of $3 \times 1017 \mathrm{~N} 2+$ at 450 and $600^{\circ} \mathrm{C}$ implantation temperatures, the $\mathrm{B}$ film transformed to hexagonal boron nitride with lower friction coefficient and lower hardness. When enhanced the ion energy to $100 \mathrm{keV}$ for hardening and then implanted in the same conditions as the previous case, Knoop microhardness increased significantly and the friction coefficients dropped to a much lower level.

\section{B. Diamond coatings on titanium alloy substrate}

Diamond coatings also attracted much attention of researchers in the past decade. L. Vandenbulcke and D.R. Herbin [2] applied microwave plasma reactor to produce diamond coating in $\mathrm{CH} 4-\mathrm{H} 2$ and $\mathrm{CO}-\mathrm{H} 2$ mixture atmosphere. Diamond layers with 1-10 $\mu \mathrm{m}$ thickness were obtained at lower temperature of $600{ }^{\circ} \mathrm{C}$ with a fairly good crystallinity and residual stress. This method overcame the disadvantage of peeling off during cooling down from the deposition to room temperature when higher deposition temperature is used.

Liu [3] studied the wear mechanism of diamond-like carbon films. DLC films were coated on metallic substrate (Ti-6Al-4V) by methane ion-beam deposition. The DLC films possess excellent wear resistance and exhibit low values of friction coefficient $(f<0.1)$. The frictional response was characterized by an initial break-in period that was followed by an intermediate constant $f$ stage. When carrying out wear test, a carbon transfer layer was observed on the wear scars of ball surfaces. It was verified that transfer layer contained a fine distribution of graphite nanoparticles (less than $5 \mathrm{~nm}$ ) in a distorted diamond-like structure. Laser Raman spectra taken from the wear track region also revealed evidence of graphitization. In light of those observations, the intermediate friction stage was mainly attributed to transfer layer formation. During long-duration wear experiments, a further reduction in $\mathrm{f}$ was observed that finally reached steady state low friction $(\mathrm{f}=0.05-0.07)$ and an ultra-low wear rate (about $1.6 \times 10-9 \mathrm{~mm} 3 \mathrm{~m}-1 \mathrm{~N}-1)$. Steady state was related to the complete transformation of diamond-like to graphite-like carbon under thermal and strain effects from the repeated 
friction through a precursor stage involving hydrogen evolution. The ultra-low wear rates were correlated to easy shear of low-strength atomic carbon interlayers in the graphitic structure.

Diamond coatings, although exhibit properties like the highest hardness, the highest conductivity of heat of all known materials, additionally, possess hydrogen-saturated surfaces by chemical vapor deposition(CVD) method, which results in low friction, as-deposited diamond films usually lead to severe abrasive wear of the counter bodies caused by the relatively sharp facets of the CVD-diamond films. Therefore, laser or plasma polishing processes would be followed after coating, as reported by E. Zeiler [4].

It was found that hydrogen trapped in the deposited single layer diamond-like films can produce high tensile stress, leading to embrittlement and buckling. High internal stresses may cause poor adhesion of diamond-like carbon(DLC) films on substrate. Choy [5] achieved a new method for functionally graded coating to improve the adhesion of the DLC films on metallic substrates.

In their study, the FGM is a compositionally graded coating where two neighboring layers have at least one common element. Consequently, the layers have graded interfaces that ensure no abrupt change in composition, and therefore the coated system has minimal stress concentration. The compositionally graded coating system investigated was $\mathrm{Ti} / \mathrm{TiN} / \mathrm{TiNC} / \mathrm{DLC}$ and $\mathrm{Ti} / \mathrm{TiC} / \mathrm{DLC}$ on titanium alloy substrates. The coatings were deposited using a magnetron sputter ion plating method. Graphite and titanium targets were used to provide the $\mathrm{C}$ and $\mathrm{Ti}$. Acetylene and nitrogen gases were also used to provide the $\mathrm{C}$ and $\mathrm{N}$ in the films. The films had the expected compositions in each layer and the adhesion was successfully improved.

In order to improve the film-substrate adhesion, non-hydrogenated, tetrahedrally-bonded amorphous carbon (ta-C) thin films by some researchers [6-9] using filtered cathodic arc plasma dposition. It has been shown that this coating material has same biological compatibility and other desirable characteristics of a-C:H, with the additional advantage of being extremely hard, with hardness values approaching that of pure diamond. Unfortunately, it is frequently the case that these very hard ta- $\mathrm{C}$ coatings also trend to delaminate from the substrate, a behavior which is generally associated with the high internal stress of the film.

Tong [10] adopted a carbon ion pre-implantation method to improve the bonding strength. The Ti-6Al-4V substrate material was firstly treated before ta-C formation by filtered cathodic arc plasma deposition. Carbon ion implantation was carried out using a metal vapor vacuum arc ion implantation facility. Following carbon ion implantation, the ta-C coating was carried out in another vacuum chamber. By optimizing the ion energy(approx. $100-150 \mathrm{eV})$, films with very high fraction of diamond-like sp3 bonding were obtained. Hence possesses a higher wear resistance. With the pre-implantation, the adhesion of the coatings reached to a higher level of $0.75 \mathrm{GPa}$ than that without pre-implantation. Microstructure analysis indicated an atomically mixed interface zone between the ta-C film and the Ti-6Al-4V substrate.

Nanocrystalline and multilayer diamond coatings were fabricated and the wear behavior was investigated by Malesela J. Papo [11]. A 6kw microwave plasma chemical vapor deposition reactor was used to deposit thin films on polished condyle and fossa substrates. H2, N2 and $\mathrm{CH} 4$ combined gases were used in the chamber at $700^{\circ} \mathrm{C}$. The microstructures of the films are indicated in Fig .1.

The multilayer has superior wear properties than the single-layered film. Also, the multilayer films has higher strength than the single-layered films owing to the interface formed by the multilayer films, which was found to prevent crack propagation. The middle layer has higher diamond crystallinity and hardness than the two layers that bound it. The actual clinical use for two years showed that there was minimal damage of the NCD thin film, only showing a wear area that appears to be smoother than the slightly rougher surrounding, but without any indication of loss of film.

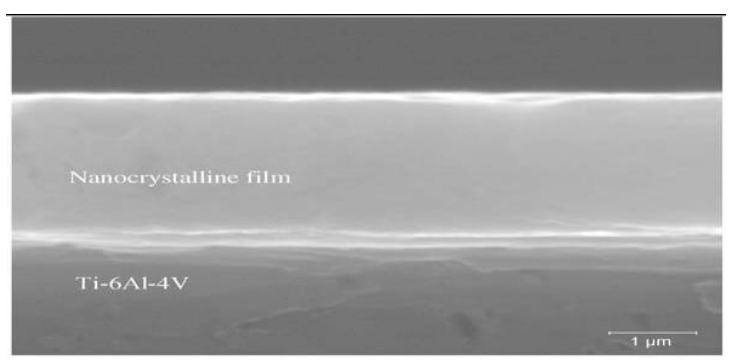

(a)

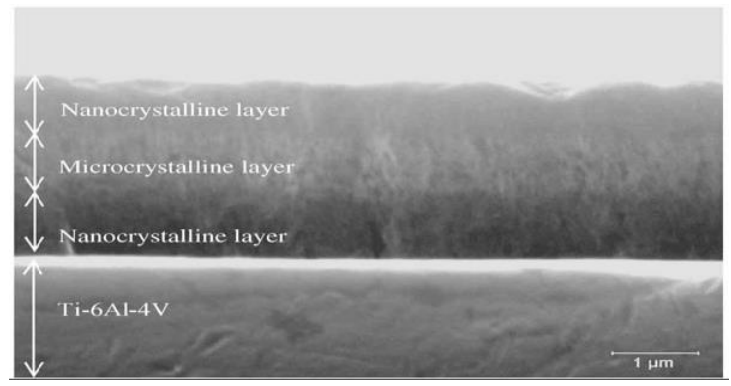

(b)

Figure 1. (a) Nanocrystalline coating (b) Multilayer nanocrystalline coating[11]

To improve the adhesion of diamond-like carbon films to Ti-6Al-4V substrate, also, metal elements like Ti, Zr, W, $\mathrm{Nb}, \mathrm{Si}, \mathrm{Cr}$ doped films were investigated by some researchers [12-19]. Transition metal, including $\mathrm{Ti}, \mathrm{Cr}, \mathrm{Zr}$ plays an important role of catalyzing the formation of DLC films because the transition metal's d-orbital trends to overlap with carbon's p-orbital.

Wang [12] fabricated a series of amorphous hydrogenated carbon films (with and without metal nitride interlayer). The films were deposited on biomedical grade ASTM F136 titanium alloy (Ti-6Al-4V) substrates using a cathodic arc evaporation (CAE) system. During the deposition process, arc evaporators were used as the metal sources, and $\mathrm{C} 2 \mathrm{H} 2$ was used as the carbon source. Three common transition metals, $\mathrm{Cr}$, $\mathrm{Ti}$, and $\mathrm{Zr}$, were selected as the cathode materials for depositing metal-containing DLC coatings of $\mathrm{Cr}-\mathrm{C}: \mathrm{H}$, Ti-C:H and $\mathrm{Zr}-\mathrm{C}: \mathrm{H}$, respectively. A graded metal and metal nitride interlayer were deposited to reduce the internal stress of the composite DLC coating and improve the adhesion between the DLC film and the titanium alloy substrate. The functionally graded interlayers were designed as Me-C:H/ MeN/Me/Ti-6Al-4V (Me-C:H/MeN) and Me-C:H/Me/ Ti-6Al-4V (Me-C:H). The transition layer from metal nitride to DLC was formed 
by controlling the reactive gas. The Cr-containing DLC films possessed a higher microhardness than that of Ti-C:H(2500Hv25g) and Zr-C:H(3000Hv25g). Scratch tests were conducted to determine the adhesion of the films. The results showed that the metal doped DLC films with graded nitride interlayer possess better film adhesion strength which is $57.8 \mathrm{~N}, 55 \mathrm{~N}$ and $53.5 \mathrm{~N}$ for $\mathrm{Cr}-\mathrm{C}: \mathrm{H} / \mathrm{CrN}$, $\mathrm{Ti}-\mathrm{C}: \mathrm{H} / \mathrm{TiN}$ and $\mathrm{Zr}-\mathrm{C}: \mathrm{H} / \mathrm{ZrN}$, respectively.

The friction coefficients of the metal doped DLC coatings sliding against UHMWPE counterparts were tested and listed in Wangs report [12]. The friction coefficient of the uncoated Ti alloys is 0.90 in air, and 0.69 in SBF solution. The $\mathrm{Cr}$ containing DLC films possess the lowest friction coefficient in $\operatorname{air}(0.16)$ and in simulated body fluid(SBF)(0.06) because of their dense structures. For the metal-doped DLC films, the weight losses of the UHMWPE counterparts range from 1.3 to $2.2 \mathrm{mg}$ in air at $25 \mathrm{~km}$ sliding distance and from 1.4 to $3.0 \mathrm{mg}$ in SBF at $50 \mathrm{~km}$ sliding distance.

A latest research is reported in 2012. Tiago Falcade [19] fabricated DLC films on titanium alloy by using organic liquid. Diamond-like films were obtained by electro deposition technique at room temperature, using organic liquids. The results show a very significant decrease in friction cofficient, valued 0.1. The layer thickness values were $0.33 \mu \mathrm{m}-0.59 \mu \mathrm{m}$. Higher content was also obtained by testing sp3/sp2 bonds ratio usng Raman spectrum.

\section{TiN coatings}

TiN coatings, generated by nitriding processes, have been investigated by many researchers. Up to now, there are many technologies for producing TiN coatings on Ti-6Al-4V alloy substrate, the most commonly used methods are conventional nitriding [20], conventional ion implantation [21] and its modified process, for example, source nitrogen ion implantation [22], as well as intensified plasma nitriding(PN) [23]. The surface structure is usually a composite of the delta(TiN type), epsilon $\left(\mathrm{Ti}_{2} \mathrm{~N}\right.$ type) and alpha (solid solution of nitrogen in titanium) phases, as shown in Fig .2.

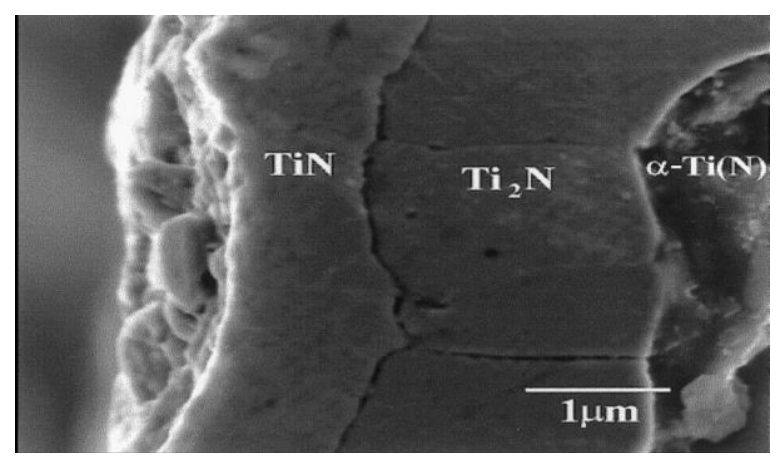

Figure 2. Compositions of surface coatings

However, in most cases, both the high nitriding temperature and long nitriding time (8-32 hours for 7-35 $\mu$ $m$ thickness layer) make the processes relatively expensive. Meanwhile, the effective adhesion of the TiN coatings is not good enough because of the lack of load support provided by the relatively soft substrate beneath the coating. As a result, delamination of TiN coatings has been observed on the surface of Ti-6Al-4V components under wear conditions.
Researchers made efforts to improve the processes to overcome these disadvantages. Until recently, a pulsed D.C. plasma-duplex process [24] and an intensified glow discharge for industrial plasma nitriding process [25] were achieved.

During the plasma-duplex process, two steps were conducted. First, pulsed D.C. plasma nitriding(PN) was performed, and then a standard 2-3 $\mu \mathrm{m}$ PCVD TiN coating was deposited on the nitrided samples. The nitrided layer and TiN coating produced by plasma-duplex processing provide a marked improvement in the wear resistance of Ti-6Al-4V alloy. The higher microhardness of the composite layer makes the wear volume very low.

Intensified glow discharge is a thermochemical surface treatment method. The glow discharge is intensified by an electron source at a low negative potential installed in addition to the cathode(substrates) and the anod. With the aid of the additional electrons the plasma density and the discharge current can be increased significantly without increasing the discharge pressure. This leads to a significant increase of average ion energy without enhancing the heating effect of the plasma. As a result, the nitriding hardness depth would be significantly increased.

A newly developed method is laser nitridation of titanium surfaces [26, 27]. The use of laser radiation for nitriding is an interesting alternative because of the orders of magnitude higher reaction rates as compared to conventional techniques. In addition, in case of short focused laser pulses, the reduced heat-affected zones both in lateral dimensions and depth ensure the accurate spatial control of the process, i.e. the change of the surface properties of the irradiated area without affecting the bulk.

\section{SURFACE CLADDING}

\section{A. Multi-layer cladding}

Coatings show both very low values for wear rate, friction coefficient and high hardness. Nevertheless, the PVD or CVD techniques allow to obtain just thin coating thickness $(<10 \mu \mathrm{m})$, which does not warrant good mechanical resistance in presence of high contact stresses, during the whole lifetime of component, especially when they are used on softer substrate like titanium alloy.

To overcome such a limit, E. Bemporad [28] fabricated a duplex coating by high oxygen fuel (HVOF PVD) thermally sprayed method. The optimized duplex coating consists of a harder and also stiffer interlayer, which allows a better distribution of contact stresses, avoiding plastic deformation of the substrate. Thermally sprayed WC-Co thick layer and a $\mathrm{TiN}$ (or $\mathrm{CrN}$ ) thin top layer were combined by the researchers to obtain superficial composite hardness, wear resistance, interfacial toughness in comparison with the single-layer PVD coating. This process was carried out firstly by coating WC $17 \%$ Co thick layer with thickness of $500 \mu \mathrm{m}$ using high Velocity Oxygen Fuel technique, then a TiN or CrN thin layers of approximately $3 \mu \mathrm{m}$ TiN and CrN PVD top coat were deposited using Cathodic Arc PVD. The composite mechanical properties such as contact load bearing capacity, adhesion, high hardness, low wear rate were significantly improved. However, as reported in the article [28], the whole coating costs are obviously higher than a traditional duplex process (nitriding plus PVD) and also applicable for very limited component geometry (due 
to the careful polishing step); nevertheless, the increase in the life time of the component could overcome its production costs for some specific applications.

Alternative coatings for Ti-6Al-4V should be dense, have good adhesion, oxidation resistance, and a low coefficient of friction. Furthermore, the coatings should have a hard primary phase to provide wear resistance and load-bearing capability and a lubricating secondary phase to reduce the friction between the two contacting components if wear debris forms. Except for the diamond-like carbon(DLC) coatings, $\mathrm{MoS}_{2}$ films have also been investigated [29]. Diamond and $\mathrm{MoS}_{2}$ have different wear and lubrication mechanisms. Diamond is naturally very hard and its friction is determined primarily by the elastic deformation of the contact region. This has very low coefficient of friction. On the other hand, $\mathrm{MoS}_{2}$ has lamellar crystal structure. Generally, a complicated pretreatment should be carried out before $\mathrm{MoS}_{2}$ coating. Wu [29] developed a simple two-step magnetron sputtering process to deposit $\mathrm{Ti} / \mathrm{MoS}_{2}$. While $\mathrm{MoS}_{2}$ provides the lubrication, the existence of $\mathrm{Ti}$ in the coating is thought to improve the adhesion of the film to the substrate.

$\mathrm{Cu}-\mathrm{Ni}$-In sputtering coated Ti-6Al-4V substrate that is currently used for turbine applications was selected as reference in his research. With the added $\mathrm{Ti}$, the $\mathrm{Ti} / \mathrm{MoS}_{2}$ films retained the good lubrication properties and load-bearing ability of $\mathrm{MoS}_{2}$, with the advantage of improved adhesion. The pull test result showed that $\mathrm{Ti} / \mathrm{MoS}_{2}$ coatings have much better adhesion ( 3 times) than the plasma-sprayed $\mathrm{Cu}-\mathrm{Ni}-\mathrm{In}$.

\section{B. Surface composite layer on Ti-6Al-4V substrate}

A lthough various coatings and nitriding treatment enhanced the wear resistance of titanium alloy, owing to the thinner hardened phase layer, the durability is low. To improve the wear resistance of these materials it is necessary to incorporate hard materials in the microstate. In recent years, surface composites have been newly developed by joining ceramic powders.

In 1997, T. Yamamoto [30] synthesized TiB/Ti composite by adding $\mathrm{B}$ to $\mathrm{Ti}$ powder using powder metallurgy. Different $\mathrm{B} / \mathrm{Ti}$ atomic ratios from 0.3-2.0 were adopted. Mixed $\mathrm{B}$ and $\mathrm{Ti}$ powders were pressed and sintered. A self propagating reaction between the Ti and $\mathrm{B}$ powders occurred above the Ti transformation temperature. A near full densities were obtained for $\mathrm{B} / \mathrm{Ti}$ atomic ratio between 0.3 and $0.4(33-44 \%$, vol. $\%$, TiB) when immediately cooled down. The microstructure consists of a Ti matrix with dispersed TiB platelets $2-30 \mu \mathrm{m}$ in size. The Vickers hardness and fracture stress of the composites had a significant improvement. The wear of the composite is approximately $7-9 \%$ of the $\mathrm{Ti}$ and $\mathrm{Ti}-6 \mathrm{Al}-4 \mathrm{~V}$.

In 2004, Eunsub Yun [31] fabricated (TiC, $\mathrm{TiB}) / \mathrm{Ti}-6 \mathrm{Al}-4 \mathrm{~V}$ surface composites to improve the high temperature hardness and strength of the structures such as engine parts of supersonic airplanes or spaceships. A high-energy electron-beam irradiation method was employed. Ti-6Al-4V was used as substrate and $\mathrm{TiC}, \mathrm{TiB}_{2}$, and $\mathrm{B}_{4} \mathrm{C}$ powders were placed on its surface, then irradiating a high-energy electron beam(see Fig .3). At the same time, flux was used to protect the melted powders and substrate from the air and to promote homogeneous melting.
The surface composite layer consists of eutectic TiB, primary $\mathrm{TiB}$ and primary TiC. Vickers hardness was tested and compared with those of TiC/Ti-6Al-4V and TiB/Ti-6Al-4V. Owing to abundant precipitation, the hardness of (TiC, TiB/Ti-6Al-4V) is twice as much the hardness of Ti-6Al-4V, while it is higher than $\mathrm{TiC} / \mathrm{Ti}$ Al-4V and lower than TiB/Ti-Al-4V, because of the higher hardness of the matrix of TiB/Ti-6Al-4V. In addition, the higher hardness maintained up to $450^{\circ} \mathrm{C}$ because $\mathrm{TiC}$ and $\mathrm{TiB}$ particles were thermally stable and in soluble at high temperatures over $90^{\circ} \mathrm{C}$.

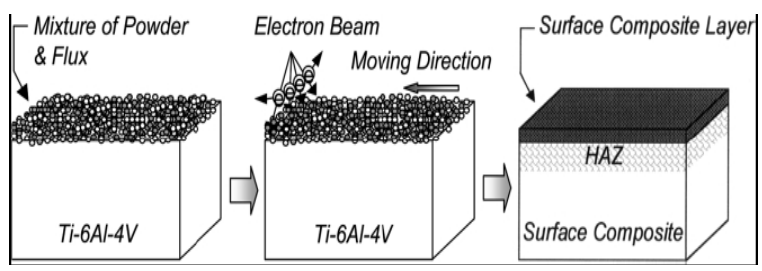

Figure 3. Schematic diagram of the fabrication procedures [31]

The surface composite layer consists of eutectic TiB, primary $\mathrm{TiB}$ and primary TiC. Vickers hardness was tested and compared with those of TiC/Ti-6Al-4V and TiB/Ti-6Al-4V. Owing to abundant precipitation, the hardness of (TiC, TiB/Ti-6Al-4V) is twice as much the hardness of Ti-6Al-4V, while it is higher than TiC/Ti6Al-4V and lower than TiB/Ti-Al-4V, because of the higher hardness of the matrix of TiB/Ti-6Al-4V. In addition, the higher hardness maintained up to $450{ }^{\circ} \mathrm{C}$ because $\mathrm{TiC}$ and $\mathrm{TiB}$ particles were thermally stable and in soluble at high temperatures over $900^{\circ} \mathrm{C}$.

The same process was adopted to fabricate $\mathrm{SiC} / \mathrm{Ti}-6 \mathrm{Al}-4 \mathrm{~V}$ surface composites to enhance hardness and improve wear resistance by the same research group. This was reported in their previous paper [32]. In the thick surface layer(1.7-2.1mm), a considerable amount of large hexagonal-pillar-shaped primary $\mathrm{Ti}_{5} \mathrm{Si}_{3}$ particles are distributed in the martensitic matrix. The primary $\mathrm{Ti}_{5} \mathrm{Si}_{3}$ are formed inside the melted metal and grown in a hexagonal pillar shape, whereas TiC particles, exist in spherical form. The hardness of $\mathrm{Ti}_{5} \mathrm{Si}_{3}$ is $930 \mathrm{VHN}$ and TiC is $1980 \mathrm{VHN}$. With these two hard phases in the matrix(its hardness is $415 \mathrm{VHN})$, the hardness of the composite layer attained to $820 \mathrm{VHN}$. As a result, wear resistance of the surface composite layer increased by 25 times.

A research on surface composite layer conducted by Yun [33] using high-energy electron-beam irradiation method was reported in 2005. In their research, Ti-based surface composites were fabricated by evenly depositing $\mathrm{TiC}$ and TiN ceramic powders on a Ti-6Al-4V alloy substrate and then irradiating high-energy electron beam. The layer consists of dendritic and spherical precipitations of $\operatorname{Ti}\left(\mathrm{C}_{\mathrm{x}} \mathrm{N}_{1-\mathrm{x}}\right)$, N-rich acicular a -Ti matrix. $\mathrm{N}$ dissolved from TiN plays a role in forming the $\mathrm{N}$-rich acicular a $-\mathrm{Ti}$ matrix and in causing solid-solution hardening of the matrix. $\mathrm{N}$ dissolution increased the hardness by 3 times of the substrate. Upon irradiation, $\mathrm{TiC}$ and $\mathrm{TiN}$ powders are melted, mixed, and solidified to form a large amount of $\operatorname{Ti}\left(\mathrm{C}_{\mathrm{x}} \mathrm{N}_{1-\mathrm{x}}\right)$, thereby leading to the excellent hardness.

A most attracting research field in recent years is Laser clading. Laser cladding is a flexible process which can be 
used to enhance the lifetime of components and repair them when worn. This is especially relevant where components are highly valued, and therefore costly to replace.

Tian [34] fabricated a (TiC, TiB/Ti-6Al-4V) composite surface layer on Ti-6Al-4V substrate by laser alloying method. The original powders are graphite and boron. They were blended with dilute sodium silicate solution to make slurry and coated on the substrate, then dried. A continuous wave $\mathrm{CO}_{2}$ laser was employed to melt the surface of samples and the tracks were partly overlapped. During the melting, argon was used as shielding gas. Compounds formed in the coatings. The composite layer contains fine $\mathrm{TiC}, \mathrm{TiB}$ dendritic particles and $\mathrm{Ti}_{3} \mathrm{O}$ and some pores. The hard ceramic compounds of $\mathrm{TiC}$ and $\mathrm{TiB}$ are evenly distributed in the matrix, thus resulted in very high hardness. So, the composite coatings exhibit excellent wear property due to their outstanding resistance to micro-cutting and plowing during dry sliding wear process.

R. Banerjee [35] fabricated in situ Ti-6Al-4V/TiB composites by a novel method-direct laser deposition. Ti-alloy/TiB composites combine the high strength and stiffness of the borides with the toughness and damage tolerance of Ti-alloy matrix and offer attractive properties such as increased stiffness, enhanced elevated temperature strength, good creep performance, fatigue resistance and wear resistance. In situ composites offer additional advantages. The boride reinforcement is formed as a consequence of an in situ chemical reaction resulting in a homogeneous dispersion of borides. Furthermore, the boride phase that forms in these in situ composites is in thermodynamic equilibrium with the matrix, an important characteristic for extended high temperature service. A high power pulsed Nd:YAG laser source is used. The laser beam is focused on the substrate to create a melt pool into which the powder feedstock is delivered through an inert gas flowing through multi-nozzle assembly. The composites were deposited from a blend of pure pre-alloyed Ti-6Al-4V and elemental B powders mixed in the ratio of $98 \%$ (wt.\%) Ti-6Al-4V+2\%wt.\%B. Acicular (needle-like) TiB with length of $1-5 \mu \mathrm{m}$ precipitated in the Ti-6Al-4V matrix uniformly as shown in Fig .4.

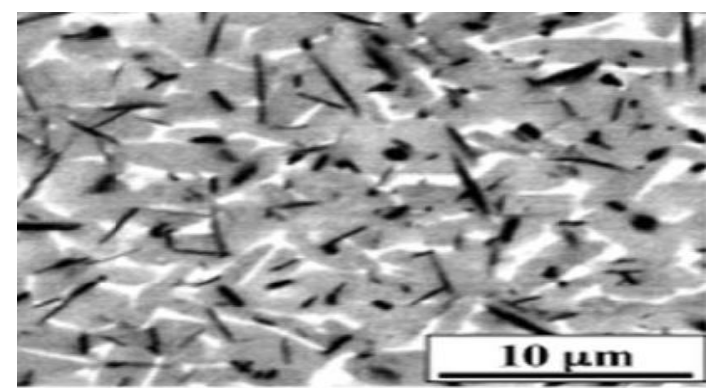

Figure 4. Acicular TiB in Ti-6Al-4V substrate[35]

Laser cladding on Ti-6Al-4V substrate by multi-element containing pre-alloyed powders like $\mathrm{NiCrBSi}$ was conducted by Sun [36]. The alloy contains $\mathrm{Cr}$, $\mathrm{B}, \mathrm{Si}, \mathrm{C}, \mathrm{Fe}$ and Ni. Clad powders were pre-placed on the surface of substrates using an organic binder. Then a laser beam focused on the powders.

The clad layer was divided into three regions: the NiCrBSi alloy clad zone, the dilution zone and the heat-affected zone in the titanium alloy. These three regions posses different hardness, showing step profile, thereby supply a stronger support to the surface zone. In the clad zone, fine particles of $\mathrm{TiB}_{2}, \mathrm{TiC}$ and $\mathrm{M}_{23}(\mathrm{CB})_{6}$ are distributed in the matrix of the primary $\gamma-\mathrm{Ni}$ and the multi-phase eutectic consisting of $\gamma-\mathrm{Ni}, \mathrm{Ni}_{3} \mathrm{~B}$ and silicides. Compared with the titanium alloy, the laser clad layer had a wear rate an order of magnitude less.

The authors improved their previous research and fabricated a composite layer by mixing TiC powders with NiCrBSi pre-alloyed powders in 2001[37]. Similar to the previous result, the clad layer is divided into the clad zone, the dilution zone and the heat-affected zone. Most of the original $\mathrm{TiC}$ particles in the cladding zone were melted due to laser radiation, and solidified to form dendrites during cooling. In the dilution zone, TiC exists in the form of well-developed dendrites that are distributed in the matrix of titanium alloy. With TiC addition, the hardness of the cladding layer has been improved, compared with the results reported in the previous paper [36].

A laser injection of WCp was reported by Vreeling [38]. In the process, a high power laser beam is used to locally melt the top layer of a metal (Ti-6Al-4V) substrate, while simultaneously a ceramic powder is injected into the melt pool. During rapid solidification of the substrate the particles are trapped and a metal-matrix composite (MMC) layer is formed, while the bulk is unimpaired(see Fig .5). WC particles may have good bonding with $\mathrm{Ti}$ alloy. Because of the high affinity of $\mathrm{Ti}$ for $\mathrm{C}$, a chemical reaction between WC particle and Ti matrix occurs during the laser process, where TiC is formed. This would result in the formation of reaction layer between the particles and matrix, which may improve the wetting and may therefore improve the bonding.

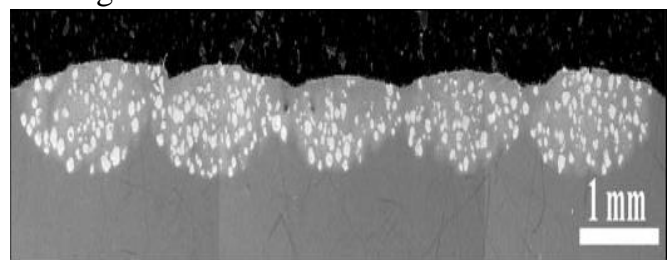

Figure 5. SEM micrograph of a cross-section of laser tracks [38]

The micrograph of the laser is shown in Fig .5. Substantial improvement of wear resistance is observed for WC/Ti-6Al-4V surface layer in comparison with substrate alloy.

P. K. Farayibi [39] reported a laser clad method of Ti-6Al-4V/WC composite on Ti-6Al-4V substrate in a latest report. In comparison to $\mathrm{Ti}-6 \mathrm{Al}-4 \mathrm{~V}$, the proposed Ti-6Al-4V/WC composite exhibited much higher erosion resistance with erosion rates up to $1 / 13$ and $1 / 8$ of that of Ti-6Al-4V under the same erosion conditions in PWJ(plain waterjet) and $\mathrm{AWJ}($ abrasive waterjet) impingement respectively. The overall performance of the Ti-6Al-4V/WC composite is attributed to the embedded WC particles and the uniformly distributed nano-sized reaction products ( $\mathrm{TiC}$ and $\mathrm{W}$ ) reinforcing the ductile $\mathrm{Ti}$ composite matrix.

\section{CONCLUSION}

Titanium and its alloys are widely used in chemical, mechanical, medical and biological applications for the excellent properties such as low density, corrosion resistance and high strength. However, the poor hardness 
and wear resistance are common drawbacks that restrict their further application. Poor tribological properties may reduce the life span and cause severe problems especially for using in human body as replacement. Thus far many efforts have been made to improve wear resistance and some techniques have been developed. Theses techniques can be classified into two categories: surface coating and surface cladding. Surface coatings generally includ BN film, diamond-like carbon films and TiN films. These surface thin layers very significantly enhance the tribological properties although the some disadvantages still exist such as the small thickness, unstable composition, and poor adherence to substrate.

Very much important achievement is surface cladding. These methods compeletly overcome the drawbacks of surface coating. Not only the thickness of the surface composite layers can be controlled but the composition of the layer can be flexiblely choiced as well. Therefore diversified composite layers can be obtained. Because the composite layers are fabricated by fusing the mixed powders on the substrate at high temperatures, the bonding strength between the surface layer and the substrate is very high. Among those, the laser beam cladding is a cutting edge and a promising method because the concentrated light beam and very high temperature can melt most of hard phase without changing the properties of the substrate.

\section{REFERENCES}

[1] T. Baazi, "Tribomechanical properties of ion-implantation systhesized BN films and their dependence on Ti-6Al-4V substrate hardness," Surface and Coating Technology, vol.72, pp.120-127, 1995.

[2] L. Vandenbulcke, D. Rats, R. Herbin, "Diamond coating of titanium alloys at tempering temperature," Materials Letters, vol.27, pp.77-88, 1996.

[3] Y. Liu, A. Erdemir, "A study of the wear mechanism of diamond-like carbon films," Surface and Coatings Technology vol.82, pp.48-56, 1996.

[4] E. Zeiler, D. Klaffke, "Tribological performance of mechanically lapped chemical vapor deposited diamond coatings," Surface and Coatings Technology, vol.116-119, pp.599-608, 1999.

[5] K.L. Choy, E. Felix, "Functionally graded diamond-like carbon coatings on metallic substrates," Materials Science and Engineering vol.A278, pp.162-169, 2000.

[6] H. H. Tong, O. R. Monteiro, "Effects of carbon ion pre-implantation on the mechanical properties of ta-C coatings on Ti-6Al-4V", Surface and Coatings Technology, vol.136, pp.211-216, 2001.

[7] S. Anders, A. Anders, Surface Coating Technology, vol.69, pp.388, 1994.

[8] B. K. Tay, X. Shi, “Thin Solid Films,” vol.309, pp.199, 1997.

[9] D.O., O. R. Monteiro, Surface Coating Technology, Vol.109, pp.484, 1998.

[10] H. H. Tong, O. R. Monteiro, "Effects of carbon ion pre-implantation on the mechanical properties of ta-C coatings on Ti-6Al-4V", Surface and Coatings Technology, vol.136, pp.211-216, 2001.

[11] M. J. Papo, S. A. Catledge, "Mechanical wear behavior of nanocrystalline and mutilayer diamond coatings on temporomandibular joint implants," Journal of Materials Science: Materials in medicine, vol15, pp.773-777, 2004.

[12] D. Y. Wang, Y. Y. Chang, "Deposition of diamond-like carbon films containing metal elements on biomedical Ti alloys," Surface and Coatings Technology, vol.200, pp.2175-2180, 2005.

[13] S. Yang, D. Camino, A. H. S. Jones, Surf. Coat. Technol, vol.124 pp.110, 2000.

[14] O. Wanstrand, M. Larsson, Surface Coating Technology, vol.111 pp.247, 1999.
[15] V. V. Glov, A.K. Kuleshov, Surface Coating Technology, vol.129 pp.150, 2000.

[16] K. Bewilogua, C. V. Cooper, Surface Coating Technology, vol.132, pp. $275,2000$.

[17] A. A. Voevodin, J. P. O’Neill, Thin Solid Films, vol.342, pp.194, 1999.

[18] M. Stuber, S. Ulrich, Surface Coating. Technology, vol.116-119 pp.591, 1999

[19] Tiago Falcade, "Electro deposition of diamond-like carbon films on titanium alloy using organic liquid: Corrosion and wear resistance," Applied Surface Science, vol.263, pp.18-24, 2012.

[20] J. S. Chen, S. P. Lau, Thin Solid Films, vol. 110, pp.398-399, 2001

[21] J. S. Kawalec, S. A. Brown, Transaction of Biomaterial Society, vol.18, pp.355, 1995.

[22] C. Badini, C. Gianoglio, Journal of Less-Common Metal, vol.143, pp.129, 1988.

[23] F. Dlai, T. I. Wu, Surface Coating. Technology, vol.58, pp.79, 1993.

[24] X. Qiu, J. R. Conrad, R. A. Dodd, F. J. Worzala, Metallic, Transaction, vol.A 21 pp.1663, 1990.

[25] Shengli Ma, Kewei Xu, Wanqi Jie, "Wear behavior of the surface of Ti-6Al-4V alloy modified by treating with a pulsed D.C. plasma-duplex process," Surface and Coatings Technology, vol.185, pp.205-209, 2004

[26] J. D. Majumdar, "Laser Gas Alloying of Ti-6Al-4V," Physics Procedia, vol.12, pp.472-477, 2011.

[27] A. G. Reis, "Creep behavior study at $500 \mathrm{C}$ of laser nitrided Ti-6Al-4V alloy, " Journal of Material. Research Technology, vol.2(1), pp.48-51, 2013.

[28] E. Bemporad, "Production and characterization of duplex coatings (HVOF and PVD) on Ti-6Al-4V substrate," Thin Solid Films vol.515, pp.186-194, 2006.

[29] L. Wu, B. C. Holloway, "Analysis of diamond-like carbon and Ti/MoS2 coatings on Ti-6Al-4V substrates for applicability to turbine engine applications," Surface and Coatings Technology , vol.130, pp.207-217, 2000.

[30] T. Yamamoto, A. Otsuki, K. Ishihara, "Synthesis of near net shape high density TiB/Ti composite," Materials Science and Engineering vol.A239-240,pp.647-651, 1997.

[31] E. Yun, K. Lee, S. Lee, "Improvement of high-temperature hardness of (TiC, TiB)/Ti-6Al-4V surface composites fabricated by high-energy electron-beam irradiation," Surface and Coatings Technology, vol.184, pp.74-83, 2004.

[32] J. C. Oh, E. Yun, M. G. Golkovski, S Lee, "Improvement of hardness and wear resistance in SiC/Ti-6Al-4V surface composites fabricated by high-energy electron beam irradiation," Materials Science and Engineering, vol.A351, pp.98-108, 2003.

[33] E. Yun, K. Lee, S. Lee, "Correlation of microstructure with high-temperature hardness of (TiC,TiN)/Ti-6Al-4V surface composites fabricated by high-energy electron-beam irradiation," Surface and Coatings Technology, vol.191, pp.83-89, 2005.

[34] Y. S. Tian, C. Z. Chen, "Study on the microstructure and wear resistance of the composite coatings fabricated on Ti-6Al-4V under different processing conditions," Applied Surface Science, vol.253, pp.1494-1499, 2006.

[35] R. Banerjee, P. C. Collins, A. Genc, "Direct laser deposition of in situ Ti-6Al-4V-TiB composites," Materials Science and Engineering, vol.A358, pp.343-349, 2003.

[36] R. L. Sun, D. Yang, "Microstructure and wear resistance of NiCrBSi laser clad layer on titanium alloy substrate, Surface and Coatings Technology, vol.132, pp.251-255, 2000.

[37] R. L. Sun, D. Yang, Z. L. X. Guo, "Laser cladding of Ti-6Al-4V alloy with $\mathrm{TiC}$ and $\mathrm{TiC}+\mathrm{NiCrBSi}$ powders," Surface and coating Technology, vol.135, pp.307-312, 2001.

[38] J. A. Vreeling, V. Ocelik, "Ti-6Al-4V strengthened by laser melt injection of WCp particles," Acta Materialia, vol.50, pp.4913-4924 2002.

[39] P.K. Farayibi, "Erosion resistance of laser clad Ti-6Al-4V/WC composite for waterjet tooling," Journal of Materials Processing Technology, vol.214, pp.710-721, 2014. 